\title{
On evaluating applied water balance research
}

\author{
Ph. Th. Stol
}

Institute for Land and Water Management Research, Wageningen, The Netherlands

Received 6 June, 1968

\section{Summary}

The formula for the water balance, which is shown to be more than a collection of abbreviations, exists of the summation of several terms. Each term represents the value obtained after investigating the phenomenon described by that term. The visible result of the balance, the amount of water discharged from a watershed, can be measured directly or can be forecasted with the aid of the other terms of the balance. Progress in knowledge of the terms or of the balance as a whole, is obtained if, after each new investigation large discrepancies between observed and forecasted values occur with smaller probabilities of exceedance. The relationship between these probabilities and an a priori given size of the discrepancies is dealt with in this paper and the advantage of knowledge of the corresponding distribution functions is shown. Application of these ideas to all terms of the balance separately is an aid in making applied research decisions when the practical requirements are known.

\section{Introduction}

The well-known formula for the water balance collects the components that have to be taken into account in water balance investigations. In this paper for the balance of the formula the visible result is taken, namely the amount of water leaving the studied area.

In our case the water balance is expressed as the following algebraic sum of terms

$\mathrm{D}=\mathrm{R}+\mathrm{S}-\mathrm{E}-\mathrm{O}-\triangle \mathrm{W}$

where

$D=$ discharge of a certain catchment area in a time-interval $t_{i+1}-t_{i}$;

$\mathrm{R}=$ precipitation in the same units and time-interval;

$S=$ seepage into the area, ibid;

$\mathrm{E}=$ evapotranspiration, ibid;

$\mathrm{O}=$ other terms, for instance representing a withdrawal of water.

Now D, R, S, E and $\mathrm{O}$ stand for sums of amounts over time-intervals, so as a matter of fact

$\mathrm{D}=[\mathrm{D}]_{\mathrm{i}}^{\mathrm{i}+1}, \mathrm{i}=0,1,2, \ldots$

The differential operator $\triangle$ acts on the argument $W$ being the amount of waterstored at time $t_{i}$, according to the rule 
$\triangle \mathrm{W}=\left(\mathrm{W}_{\mathrm{i}+1}-\mathrm{W}_{\mathrm{i}}\right)$

Thus defined, no ambiguity with respect to the sign of $\triangle W$ will occur.

\section{Properties of the water balance formula}

Formula (1) is supposed to represent the true values assumed by the quantities mentioned and to express the fact that no matter can be gained or lost. The length of the time-interval is irrelevant in the following considerations because, taking sums over $\mathbf{N}$ such intervals (2) for instance yields

$$
\sum_{\mathrm{j}=\mathrm{Ni}}^{\mathrm{N}(\mathrm{i}+1)-1}[\mathrm{D}]_{\mathrm{j}}^{\mathrm{j}+1}=[\mathrm{D}]_{\mathrm{Ni}}^{\mathrm{N}(\mathrm{i}+1)}, \mathrm{i}=0,1,2, \ldots
$$

with time-interval $t_{\mathrm{N}(\mathrm{i}+1)}-\mathrm{t}_{\mathrm{Ni}}$. Analogous results are obtained for the other terms of (1). The difference in amount of water stored between the limits of the time interval becomes

$$
\begin{aligned}
& \sum_{j=N i}^{N(i+1)-1} \triangle W=\sum_{i=N i}^{N(i+1)-1}\left(W_{j+1}-W_{i}\right)= \\
& =W_{N i+1}+W_{N i+2}+\ldots+W_{N(i+1)}-W_{N i}-W_{N i+1}-\ldots-W_{N(i+1)-1}= \\
& =W_{N(i+1)}-W_{N i}
\end{aligned}
$$

Taking time units $\mathbf{N}$ times as large, (2a) and (3a) again take the forms (2) and (3). So, evidently, eq. (1) itself can also be considered to be built up from more elementary sums. In our case the time-interval is supposed to be small, in the order of magnitude of days.

\section{Comparable situations}

A certain meteorologic situation, which potentially may cause a situation $\mathbf{M}_{\mathbf{0}}, \mathbf{M}_{1}, \ldots$, and coincides with initial conditions of hydrologic kind in the area under consideration, say $H_{0}, H_{1}, \ldots$, causes a total situation represented by the symbols $C_{0}, C_{1}, \ldots$, $\mathrm{C}_{1}, \ldots$, where it is assumed that each of them can occur frequently.

So one can speak of the $i$-th realization of situation $\mathrm{C}_{0}$, written as $\left(\mathrm{C}_{0}\right)_{i} *$.

The $i$-th realization of a situation which potentially causes $C_{0}$ can be written as the equality of the true values

$\left(\mathrm{D}_{0}\right)_{\mathrm{i}}=\left(\mathrm{R}_{0}\right)_{\mathrm{i}}+\left(\mathrm{S}_{0}\right)_{\mathrm{i}}-\left(\mathrm{E}_{0}\right)_{\mathrm{i}}-\left(\mathrm{O}_{0}\right)_{\mathrm{i}}-\left(\Delta \mathrm{W}_{0}\right)_{\mathrm{i}}$

As a matter of fact in water balance research-practice the situation is quite different from that considered thus far. Regardless of measurement errors true values are not

* We are not concerned here with the problem how to detect equality of situations but it must be emphasized that a full description of situations $\mathrm{C}$ must necessarily be made, because only then there will be the possibility of comparing results mutually. 
known and the available values to be inserted in (1) are estimates of those which should have been taken to obtain eq. (4). Reason for this is that the values of most of the variables occurring in a water balance cannot be measured directly, but are results of investigations on the behaviour of the phenomena themselves. This means that the available values are parameters $(\Theta)$ of the true ones. One might even say that the variables occurring in a water balance equation themselves are parameters. So (1) has to be replaced by (5) which reads

$\Theta_{\mathrm{R}}+\Theta_{\mathrm{S}}-\Theta_{\mathrm{E}}-\Theta_{\mathrm{O}}-\Theta_{\triangle \mathrm{W}}=\Theta_{\mathrm{D}}$

where $\Theta_{D}$ now indicates the result of the algebraic sum of the terms on the left of the equality sign. To express the fact that the values of the $\mathrm{i}$-th realization of $\mathrm{C}_{0}$ are used we write $\Theta_{\mathrm{R}_{\mathrm{i}}}, \ldots, \Theta_{\mathrm{D}_{\mathrm{i}}}$, leaving it understood that $\mathrm{C}_{0}$ is meant.

\section{Obtaining parameter values}

The parameters $\Theta$ are of quite different shape depending on the structure of the phenomenon represented by their subscripts. A short discussion can be given to indicate the variated type of problems whose solutions enter the water balance equation. It is obvious, in the case of rainfall, to chose a function of directly measured rainfall amounts $R$ so

$\Theta_{\mathrm{R}}=\mathrm{f}_{\mathrm{R}}(\mathrm{R})$

In other words: a working value for the component rainfall $\left(\Theta_{\mathrm{R}_{\mathrm{i}}}\right)$ is obtained from the rainfall phenomenon. This rainfall function is sometimes chosen in such a way that $f_{R}$ contains the procedure of determining rainfall amounts from isohyetal analyses, or the weighted mean obtained from a Thiessen network, or a simple arithmetic mean. A trivial function, which can be used for small areas with a nearby rainfall station, so assuming uniformly distributed rainfall amounts, is the identity

$\Theta_{\mathrm{R}_{\mathrm{i}}}=\mathrm{f}_{\mathrm{R}}\left(\mathrm{R}_{\mathrm{i}}\right)=\mathrm{R}_{\mathrm{i}}$

More complicated functions, for example, are those which account for the delay caused by a low infiltration rate of precipitation into the soil and the delay caused by the flow through ditches and canals before reaching the point where the water leaves the watershed or polder.

The seepage into a region depends on the hydrologic and geologic properties of the area under consideration, so in general

$\Theta_{\mathrm{S}}=\mathrm{f}_{\mathrm{S}}($ hydrology, geology)

In this case $\mathrm{f}_{\mathrm{S}}$ might be considered to symbolize the total amount of work to be done in order to obtain a measure for seepage, involving geohydrologic investigations. Even when direct observations are used, as proposed by Van Der Weerd (1965), the identity between working values and measured values, analogous to (6), is a too simple relationship because of irregularities due to differences in groundwater level, hydraulic conductivity of layers building up the drainage basin, distances from the boundaries of the watershed, and so on. Integration with respect to time and area still has to be performed so at least 
$\Theta_{\mathrm{S}_{\mathrm{i}}}=\mathrm{f}_{\mathrm{S}}\left(\mathrm{S}_{\mathrm{i}}\right.$, time, area $)$

About the same kind of reasoning can be followed for the evapotranspiration term. Integration with respect to area will have to be performed, but also farm practice methods as cropping pattern have to be taken into account, so farm management analyses will have to be done. In about the same way other terms are to be dealt with. Direct determination of the storage is possible with the aid of a network of test wells from which differences in storage can be derived. Here the relation

$\Theta_{\triangle \mathrm{W}}=f_{\mathrm{W}}(\mathrm{W})$

represents rather a method than a well-defined function in the sense of a mathematical description.

\section{Checking the water balance}

Finally eq. (5) results in the amount of discharge which is a parameter value too. The true value is not known but with direct observations in a stream this value can be estimated. Assuming that the observations may serve as a check on the calculated water balance, resulting in (5), the working values are to be compared with these observations so

$\Theta_{\mathrm{D}_{\mathrm{i}}}=\left(\mathrm{D}_{0}\right)_{\mathrm{i}}+\delta\left(\mathrm{D}_{0}\right)_{\mathrm{i}}$

which means that the parameter (working) values obtained by eq. (5) will differ from the true values $\left(D_{0}\right)_{i}$ by the amount $\delta\left(D_{0}\right)_{i}$ the $\mathrm{i}$-th time that the situation $\mathrm{C}_{0}$ occurs and a forecast about the discharge is made.

Graphically the results can be compared by plotting

$(\mathrm{x}, \mathrm{y})=\left(\left(\mathrm{D}_{0}\right)_{\mathrm{i}}, \Theta_{\mathrm{D}_{\mathrm{i}}}\right)$

from which, empirically, the systematic trend can be derived.

Let, in general,

$\Theta_{\mathrm{D}}=\mathrm{f}_{\mathrm{D}}\left(\mathrm{D}_{0}\right)$

then, with reasonable results, which show a fair approximation to the discharge values obtained from observations, one might expect the particular form

$\Theta_{\mathrm{D}}=\alpha\left(\mathrm{D}_{0}\right)+\beta$

where $\alpha$ and $\beta$ are expected to be 1 and 0 respectively. For any particular point eq. (11) takes the form

$\Theta_{\mathrm{D}_{\mathrm{i}}}=\alpha\left(\mathrm{D}_{0}\right)_{\mathrm{i}}+\beta+\delta\left(\mathrm{D}_{0}\right)_{\mathrm{i}}$

where random-errors are made allowance for.

With respect to (12) the precision of the system of working is said to be high when the statistical error is small so that there is a high probability for the forecasted value $\Theta_{D_{i}}$ to fall in the same interval of values as $\Theta_{D_{i-1}}$ was found to do. The accuracy is said to be high when the net systematic error is small (Parrat, 1961). Taking mathematical expectations on both sides of (12) $\mathrm{E}\left(\Theta_{\mathrm{D}}\right)=\alpha\left(\mathrm{D}_{0}\right)+\beta$ so high accu- 
racy is obtained with $\alpha$ near unity and $\beta$ neglectible. Statistical methods produce measures of precision; lack of accuracy can only be detected by observing the phenomenon forecasted and careful analyses of the results thus obtained.

It will be clear that it is not easy (read: impossible) to detect what influence or term in the water balance causes the function $f_{D}$ to be present. Let $F_{D}$ stand for the inverse function of $f_{D}$ then, with eq. (5), eq. (10) becomes

$\mathrm{D}_{0}=\mathrm{F}_{\mathrm{D}}\left(\Theta_{\mathrm{R}}+\Theta_{\mathrm{S}}-\Theta_{\mathrm{L}}-\Theta_{\mathrm{O}}-\Theta_{\triangle \mathrm{W}}\right)$

which means that the result $D_{0}$ is found from an equation of the type

$\mathrm{F}_{\mathrm{D}}\left\{\mathrm{f}_{\mathrm{R}}(\mathrm{R})+\mathrm{f}_{\mathrm{S}}(\mathrm{S}\right.$, time, area $\left.)+\ldots+\mathrm{fw}_{\mathrm{W}}(\mathrm{W})\right\}=\mathrm{D}_{0}$

illustrating the impossibility to derive from eq. (10) corrections for each of the functions $f$ separately. Except for particular selected situations, for instance winter periods, $C_{1}$ say, with $E$ neglectible (Bloemen, 1968), comparison in the sense of (10) will generally speaking not lead to iterative procedures which consist of improving (6), (7), and so on, with the results derived from (10). Without further analyses it is unknown which term highly contributes to the appearance of the function $f_{D}$.

From this point on we pay our attention to discrepancies from the true values at a certain level of knowledge, say k. Furthermore we start with eq. (12) and get

$\Theta_{\mathrm{D}_{\mathrm{i}}}-\alpha_{\mathrm{k}}\left(\mathrm{D}_{0}\right)_{\mathrm{i}}-\beta_{\mathrm{k}}=\delta_{\mathrm{k}}\left(\mathrm{D}_{0}\right)_{\mathrm{i}}$

and assume $\alpha_{\mathrm{k}} \approx 1$ and $\beta_{\mathrm{k}} \approx 0$. Suppose that we are able to reach stadia $\mathrm{k}+1$, $\mathrm{k}+2, \ldots, \mathrm{k}+\mathrm{j}$, hence the parameter values continue to give a better representation of the terms occurring in the water balance equation. The consecutive stadia generally will of course not appear at mutually equal time-intervals.

\section{Deterministic approach}

Increasing insight in water balance problems, symbolically expressed by $k \rightarrow \infty$, will produce a more complete knowledge of the system as a whole. Let it now be assumed that progress in knowledge can be measured by the discrepancies $\delta$. When, after a new investigation, the process is better understood, the absolute values of discrepancies between calculated and measured values tend to become smaller. This may be expressed by

$\lim _{k \rightarrow \infty}\left|\delta_{k}\left(D_{1}\right)_{i}\right| \rightarrow 0$, any i for every 1

Which can be read: as long as $\mathrm{k}$ increases, every time the hydrologic and meteorologic situation $\mathrm{C}_{1}$ occurs, the discrepancies $\delta_{\mathrm{k}}$ tend to smaller values.

The convergency depends mainly on the choise of the situation $C_{1}$, as becomes clear by considering special situations, for instance winterperiods with small amounts of evaporation, periods with a large number of consecutive days without rainfall, and so on. These cases have the advantage of vanishing terms and a relatively better possibility of interpreting deviating results, attaching corrections to the right terms. For these situations the level of knowledge may increase faster than is found to be possible for situations needing the use of the complete formula. 
PH. TH. STOL

\section{Indeterministic approach}

As experience learns, at level $(\mathbf{k}-1)$, realizations of situation $\mathrm{C}_{1}$ may occur which incidentally produce smaller discrepancies than later on will be found after developing new and more general theories, using new devices, more advanced calculation methods, etc. We can also state that with increasing $\mathbf{k}$, some realizations of $C_{f}$ may occur with greater $\delta$ than before. Evaluating the level of knowledge $\mathrm{k}$, we require $\delta$ to be small, smaller than a fixed amount, say $\mathrm{d}_{\mathrm{k}}$. Then there will exist a small probability $\mathbf{P}$, say $w_{k}$, that a realization of situation $C_{l}$ still produces a $\delta_{k}$ greater than the criterion $d_{k}$, so

$\mathrm{P}\left\{\left|\delta_{\mathrm{k}}\left(\mathrm{D}_{1}\right)\right| \geqq \mathrm{d}_{\mathrm{k}}\right\}=\mathrm{w}_{\mathrm{k}}, \mathrm{d}_{\mathrm{k}}>0$

Increasing knowledge levels are expressed by the fact that

$\mathrm{P}\left\{\left|\delta_{\mathrm{k}+1}\left(\mathrm{D}_{1}\right)\right| \geqq \mathrm{d}_{\mathrm{k}}\right\}=\mathrm{w}_{\mathrm{k}+1}<\mathrm{w}_{\mathrm{k}}$

At the present level $\mathrm{k}$ we may require that, in the nearby future, the probability of exceedance expressed by (16) takes a value smaller than or equal to a certain probability $\mathrm{p}_{\mathrm{k}}$. This means that we expect to be able to reach, within a finite number of steps (investigations), the level $(\mathrm{k}+\mathrm{m})$ with the property

$\mathrm{P}\left\{\left|\delta_{\mathrm{k}+\mathrm{m}}\left(\mathrm{D}_{\mathrm{l}}\right)\right| \geqq \mathrm{d}_{\mathrm{k}}\right\} \leqq \mathrm{pk}_{\mathrm{k}}$

so

$\mathrm{w}_{\mathrm{k}+\mathrm{m}} \leqq \mathrm{p}_{\mathbf{k}}<\ldots<\mathrm{w}_{\mathrm{k}+\mathrm{j}}<\ldots<\mathrm{w}_{\mathrm{k}+\mathrm{i}}<\mathrm{w}_{\mathrm{k}}$

This means that large fluctuations about the true value $D_{1}$ are not impossible but that they will occur, at increasing knowledge levels, with a smaller frequency than an a priori chosen fixed exceedance probability $\mathrm{p}_{\mathrm{k}}$.

Finally, the probability that discrepancies greater than $d_{k}$ will occur tends to zero so the limiting form of (17) and (17a) reads

$\lim _{i \rightarrow \infty} w_{k+j} \rightarrow 0$

In words: the exceedance of the value $d_{k}$ being the critical difference between forecasted and measured values is then not an impossible event, but its probability is equal to zero (Kendall and Stuart, 1961).

\section{Putting new criteria}

After the first knowledge level satisfying (17a) has been reached (so $j=m$ ), the criteria $d_{k}$ and $p_{k}$ in eq. (17) are met. This means that the investigations can be finished as the required conditions are satisfied. However, new investments are going to be made and new land development projects will be executed. Given the new situation there may be, after a while, an urgent need of refining the description of the water balance, to be able to judge all aspects with more detail than before.

This means that new criteria are to be put forward, which, usually, is not done 
in so many words. To tackle the new situation one might think of defining new criteria substituting the values of the first ones, so

$\mathrm{d}_{\mathrm{k}+\mathrm{m}}<\mathrm{d}_{\mathrm{k}} \quad$ and/or $\quad \mathrm{p}_{\mathrm{k}+\mathrm{m}}<\mathrm{p}_{\mathrm{k}}$

These requirements, however, are related as presently may be shown. In most cases of research practice the criterion will only be expressed in terms of $d$ for instance $\mathrm{d}_{\mathrm{k}+\mathrm{m}}=\mathrm{r} . \mathrm{d}_{\mathrm{k}}$ with $0<\mathrm{r}<1$. The reason for this is that $\mathrm{d}$ is expressed in the units of the quantity investigated. But $\mathrm{p}$ is a probability and not in a simple way related to d. Statistical analyses have to be carried out to get an idea of the order of magnitude of the probability $\mathrm{p}$. In many cases this means that a study has to be made, results of which not being directly expressable in terms of water balance quantities. Such studies are felt to belong to quite a different discipline. It will be shown that using the relationship between $\mathrm{d}$ and $\mathrm{p}$ less manpower and time is needed to reach the same level of knowledge. In other words, after statistical analyses a more precise indication of what is required can be given without the danger to aim at unnecessarily high grades of perfection.

\section{Relationship between the two criteria}

Up to this point nothing has been said about the properties of the discrepancies $\delta_{\mathrm{k}}\left(\mathrm{D}_{1}\right)_{\mathrm{i}}$, except for the fact that they obey a distribution law. This means that $\delta_{\mathrm{k}}$ is a stochastic variable. Now we assume the mathematica! expectation to be

$\mathrm{E}\left\{\delta_{\mathrm{k}}\left(\mathrm{D}_{1}\right)\right\}=0$

and the variance

$\operatorname{Var}\left\{\delta_{\mathrm{k}}\left(\mathrm{D}_{1}\right)\right\}=\sigma_{\mathrm{k}}^{2}\left(\mathrm{D}_{1}\right)$

In the same way $\delta_{\mathrm{k}+\mathrm{i}}, \mathrm{j}=1,2, \ldots$, are stochastic variables, however, with their own distributions. The quantities $d_{k}$ and $w_{k}$ in eq. (15) are now related according to the distribution of $\delta_{\mathrm{k}}$. So each criterion $\mathrm{p}_{\mathrm{k}}<\mathrm{w}_{\mathrm{k}}$ has a solution $\mathrm{d}_{\mathrm{k}}{ }^{\prime}>\mathrm{d}_{\mathrm{k}}$ according to

$P\left\{\left|\delta_{k}\left(D_{l}\right)\right| \geqq d_{k}^{\prime}\right\}=p_{k}<w_{k}$

With the distribution of $\delta_{k}$ it is obviously not possible to satisfy both criteria $d_{k}$ and $\mathrm{p}_{\mathrm{k}}$. New investigations are needed with new approaches, new theoretical considerations and new and better tools and devices to obtain at last at a new level of knowledge a distribution which then satisfies (17). We already assumed this distribution to be that of $\delta_{\mathrm{k}+\mathrm{m}}$.

Knowledge of the shape and properties of each of the distributions makes it possible to determine each $\mathrm{w}_{\mathrm{k}+j}$ and to finish the investigations as soon as this probability is smaller than $p_{k}$, which was the case after $j=m$ steps.

\section{Required numbers of steps}

Knowing only the variance of the distribution the relationship between $d_{k}$ and $w_{k}$ can 
only be given as the inequality of Tchebycheff which reads

$\mathrm{P}\left\{\left|\delta_{\mathrm{k}}\left(\mathrm{D}_{\mathrm{l}}\right)\right| \leqq \mathrm{d}_{\mathrm{k}}\right\}=\mathrm{w}_{\mathrm{k}} \leqq \frac{\sigma_{\mathrm{k}}^{2}\left(\mathrm{D}_{\mathrm{l}}\right)}{\left(\mathrm{d}_{\mathrm{k}}\right)^{2}}$

So a higher probability of exceedance is found which is the price that must be paid by not paying attention to the shape of the distribution of $\delta_{\mathrm{k}}$ itself.

According to (19) we again require $\mathrm{p}_{k}$ to be smaller than $\mathrm{w}_{\mathrm{k}}$ which means

$\mathrm{p}_{\mathrm{k}}<\mathrm{w}_{\mathrm{k}} \leqq \sigma_{\mathrm{k}}^{2}\left(\mathrm{D}_{1}\right) /\left(\mathrm{d}_{\mathrm{k}}\right)^{2}$

With the same value of $d_{k}$ this is only possible by taking $\sigma^{2}$ smaller than at knowledge level $\mathrm{k}$, which means that a new distribution must be determined with $\sigma^{2} \mathrm{k}+\mathrm{i}$ $<\sigma^{2} \mathrm{k}$. This, again, leads to the conclusion that new, and more precise, investigations have to be carried out.

Depending on the structure of the distribution law it might occur that, after $\mathrm{m}$ steps, the situation reached is like this

$\mathrm{w}_{\mathrm{k}+\mathrm{m}} \leq \mathrm{p}_{\mathrm{k}} \leq \frac{\sigma_{\mathrm{k}+\mathrm{m}}^{2}\left(\mathrm{D}_{1}\right)}{\left(\mathrm{d}_{\mathrm{k}}\right)^{2}}<\mathrm{w}_{\mathrm{k}}$

illustrating that in the case of the equality sign, exactly the same number $m$ of steps of progress have to be done but, with the inequality sign between the 2nd and the 3rd term of (20) — that is without knowledge of the distribution of the $\delta$ 's - a larger number of steps, say $n$. In the last case the result can be expressed by

$\mathrm{w}_{\mathrm{k}+\mathrm{n}}<\frac{\sigma_{\mathrm{k}+\mathrm{n}}^{2}\left(\mathrm{D}_{1}\right)}{\left(\mathrm{d}_{\mathrm{k}}\right)^{2}} \leq \mathrm{p}_{\mathrm{k}}, \mathrm{n} \geq \mathrm{m}$

the $\mathrm{n}$-th step being the first time that an error-distribution is found with the required property. Since $\mathrm{n}$ in most cases will be larger than $\mathrm{m}$, this result means that without knowledge of the distribution function further investigations have to be done and more steps have to be made in order to be sure that the required conditions are fulfilled.

\section{Interdependence of consecutive requirements}

After having met the requirements $d_{k}$ and $p_{k}$ the process of refining will be continued by setting a new requirement. It is of interest to investigate whether something can be said about the series of consecutive steps. For convenience sake we now enlarge the index $\mathrm{k}$ with unity not sooner than the criterion $\mathrm{p}$ has been reached, so we have the series

$\mathrm{w}_{\mathrm{k}}>\mathrm{p}_{\mathrm{k}} \geq \mathrm{w}_{\mathrm{k}+1}>\mathrm{p}_{\mathrm{k}+1} \geq \mathrm{w}_{\mathrm{k} \div 2}>\mathrm{p}_{\mathrm{k}+2} \geq \ldots$

We can assume the new requirements $p$ to be related to the last found value of $w$. For example, with $0<\mathbf{r}<1$ we arrive at the chain of inequalities

$\mathrm{w}_{\mathrm{k}}>\mathrm{rw}_{\mathrm{k}} \geq \mathrm{w}_{\mathrm{k}+1}>\mathrm{rw}_{\mathrm{k}+1} \geq \mathrm{w}_{\mathrm{k}+2}>\mathrm{rw}_{\mathrm{k}+2} \geq \ldots$

If the equality signs hold, for a general term the recursion formula reads 
$\mathrm{w}_{\mathrm{k}+\mathrm{j}+1}=\mathrm{rw}_{\mathrm{k}+\mathrm{j}}, \mathrm{j}=0,1,2 \ldots$

This difference equation has an analytic solution (Levy and Lessman, 1959) making it possible to calculate each term from the initial value $w_{k}$ we started from, namely

$\mathrm{w}_{\mathrm{k}+\mathrm{i}}=\mathrm{w}_{\mathrm{k}} \mathrm{r}^{\mathrm{j}}, \mathrm{j}=0,1,2 \ldots$

With suitable transformations of $\mathbf{r}$ eq. (22) takes the form

$\mathrm{w}_{\mathrm{k}+\mathrm{j}}=\mathrm{w}_{\mathrm{k}} \mathrm{e}^{-\gamma \mathrm{i}}: \mathrm{j}=0,1,2, \ldots$

where now the constant $\gamma>0$. This represents an exponential decrease of the exceedance probability. When the consecutive results are of the form (23) the value of $y$ is the degree of improvement of the result given by the next step.

It is clear that, at a sufficiently high level of knowledge as assumed here, $\gamma$ mainly depends on the quality of the team of research-workers, the means which are available and the 'lucky-hit' when developing a new theory.

When the equality sign in eq. (21) does not hold, and this will always be the case except for situations caused by chance, the realizations of the consecutive steps of progress are connected according to

$\mathrm{w}_{\mathrm{k}}>\mathrm{rw}_{\mathrm{k}}>\mathrm{w}_{\mathrm{k}+1}=\mathrm{r}_{0} \mathrm{w}_{\mathrm{k}}>\mathrm{rw}_{\mathrm{k}+1}>\mathrm{w}_{\mathrm{k}+2}=\mathrm{r}_{1} \mathrm{w}_{\mathrm{k}+1}>\ldots$

which represents the real-life situation because it is not to be expected to reach the required $r w_{k}$ exactly. Hence after each new step the factor $r$ takes a new value, so $r$ depends on w. Now the recursion formula reads

$\mathrm{w}_{\mathrm{k}+\mathrm{j} \div 1}=\mathrm{r}_{\mathrm{j}} \mathrm{w}_{\mathrm{k}+\mathrm{j}},=0,1,2, \ldots$

This linear difference equation with variable coefficients has an analytic solution too, namely with initial value $\mathrm{w}_{\mathrm{k}}$

$\mathrm{w}_{\mathrm{k}+\mathrm{j}}=\mathrm{r}_{0} \mathrm{r}_{1} \mathbf{r}_{2} \ldots \mathbf{r}_{\mathrm{j}-1} \mathrm{w}_{\mathrm{k}}=\prod_{\mathrm{i}=0}^{\mathrm{i}-1} \mathrm{r}_{\mathrm{i}} \mathrm{w}_{\mathrm{k}}$

Once more, with suitable transformations of parameters

$\mathrm{w}_{\mathrm{k}+\mathrm{j}}=\mathrm{w}_{\mathrm{k}} \exp \left(-\sum_{\mathrm{i}=0}^{\mathrm{j}-1} \gamma_{\mathrm{i}}\right), \mathrm{j}=1,2, \ldots$

This formula gives a better description of the fact that new theories and means might give rise to a more important improvement of results than refining existing theories, because each further investigation now contributes with its own value of $\gamma$. Where (23) might be considered to express the policy with which new investigations are to be promoted, (24) is the realization of the outlined policy.

\section{Choosing further steps of research}

The above considerations referred to the discharge term in the water balance formula. The next step will be to express the probabilities $w_{k}$ in probabilities with which discrepancies between true values and working values for the other terms in eq. (1) are exceeded. Such an expression might be considered as the propagation of 
probabilities of the parts into the whole. This means that a distinction can be made between the terms which contribute highly to the final discrepancies and those which practically do not contribute to departures of forecasted terms from the true values of the discharge.

In order to be able to derive such a relationship we now assume it to be possible to check each term of the water balance equation separately for instance with investigations from other periods, other areas, other periodlengths, trivial situations, lysimeter techniques and so on. Doing so the probability distribution describing the probabilities with which discrepancies $\delta_{\mathrm{k}}\left(\mathbf{R}_{1}\right), \delta_{\mathrm{k}}\left(\mathbf{S}_{1}\right), \ldots$ of each of the terms will be exceeded, can be estimated.

Now we start with eq. (5) to which we apply the propagation-of-error law. Leaving it understood that the derivation is done for situation 1 and knowledge level $\mathrm{k}$, $f$ primes denoting derivatives with respect to the argument of the parameter function - only writing the first term in full, we arrive at

$\delta(\mathrm{D})=\left\{\mathrm{f}^{\prime}(\mathrm{R}) / \mathrm{f}^{\prime}(\mathrm{D})\right\} \delta(\mathrm{R})+\ldots=\delta\left(\mathrm{R}^{\prime}\right)+\ldots$

where the last member is defined by the second. So eq. (15) reads

$\mathrm{w}_{\mathrm{k}}=\mathrm{P}\left\{\left|\delta\left(\mathrm{R}^{\prime}\right)+\delta\left(\mathrm{S}^{\prime}\right)-\delta\left(\mathrm{E}^{\prime}\right)-\ldots\right| \geq \mathrm{d}_{\mathrm{k}}\right\}$

Using the relationship between inequalities, expressing that

$|a+b-c| \leq|a|+|b|+|c|$ we get

$\mathrm{w}_{\mathrm{k}} \leqq \mathrm{P}\left\{\left|\delta\left(\mathrm{R}^{\prime}\right)\right|+\left|\delta\left(\mathrm{S}^{\prime}\right)\right|+\ldots \geqq \mathrm{d}_{\mathrm{k}}\right\}=\mathrm{w}_{\mathrm{k}}{ }^{\prime}$

The right hand side of (25) can be solved by taking convolutions of the probability distribution of each term thus expressing $w_{k}$ in their simultaneous distribution function (Feller, 1962). An approximation of the exact treatment can be obtained further, by assuming only the distribution of all $\delta$ 's separately to be known. Now we define, according to (15) for the rainfall term

$\mathrm{P}\left\{\left|\delta\left(\mathrm{R}^{\prime}\right)\right| \geqq \mathrm{d}(\mathrm{R})\right\}=\mathrm{w}(\mathrm{R})$

with analogous expressions for the other terms of the water balance. The critical values $\mathrm{d}(\mathbf{R}), \mathrm{d}(\mathbf{S}), \ldots$, are to be chosen in accordance with the possibility of estimating the true values with a high degree of accuracy. However they cannot be chosen freely once a value $d_{k}$ in eq. (15) is taken as a criterion. Partitioning of this value results in

$\left|\delta\left(\mathrm{R}^{\prime}\right)\right|+\left|\delta\left(\mathrm{S}^{\prime}\right)\right|+\ldots \geq \mathrm{d}_{\mathrm{k}}=\mathrm{d}(\mathrm{R})+\mathrm{d}(\mathrm{S})+\ldots$

Once this condition being met one of the following events must have taken place

$\left|\delta\left(\mathrm{R}^{\prime}\right)\right|>\mathrm{d}(\mathrm{R}),\left|\delta\left(\mathrm{S}^{\prime}\right)\right|>\mathrm{d}(\mathrm{S}), \ldots$

Mathematically this means that the set of events, expressed by eq. (27), is a subset of the set consisting of the union of the events from eq. (28). As these sets are defined on the same sample space we conclude that the probability of the union of (28), $w_{k}$ " say, is greater than that of the right member of (25). Applying Boole's inequality we can enlarge this probability again by writing 
$\mathrm{w}_{\mathrm{k}} \leqq \mathrm{w}_{\mathrm{k}}{ }^{\prime} \leqq \mathrm{w}_{\mathrm{k}}^{\prime \prime} \leqq \mathrm{w}_{\mathrm{k}}(\mathrm{R})+\mathrm{w}_{\mathrm{k}}(\mathrm{S})+\mathrm{w}_{\mathrm{k}}(\mathrm{E})+\ldots$

with all probabilities $w$ assumed to be small.

With insight into the exceedance probabilities $w_{k}$ of each term and into what might be expected to lie beyond the knowledge level $\mathrm{k}$, decisions can be made about the required type of investigation and about the terms that need to be studied. The next requirement reads, according to (17)

$\mathrm{p}_{\mathrm{k}}<\mathrm{w}_{\mathrm{k}} \leqq \mathrm{w}_{\mathrm{k}}(\mathrm{R})+\mathrm{w}_{\mathrm{k}}(\mathrm{S})+\ldots$

The general solution of which is given by

$\mathrm{w}_{\mathrm{k}+1} \leqq \mathrm{r}_{\mathrm{R}} \mathrm{w}_{\mathrm{k}}(\mathrm{R})+\mathrm{r}_{\mathrm{S}} \mathrm{w}_{\mathrm{k}}(\mathrm{S})+\ldots<\mathrm{p}_{\mathrm{k}}<\mathrm{w}_{\mathrm{k}}$

where, for the first term in full (see (22) with $\mathrm{j}=1$ )

$\mathrm{r}_{\mathrm{R}} \mathrm{w}_{\mathbf{k}}(\mathrm{R})=\mathrm{w}_{\mathbf{k}+1}(\mathrm{R})$, and so on

and at least one of the r's is not equal to zero.

Equation (30) has many solutions so additional conditions must be put forward. They are of course of the type that the required rate of progress must be obtained with smallest possible amount of means and here research policy enters the problem.

Cases to be looked for are those for which the exceedance probability $w$ has the highest value and decreasing this value by the factor $r$ is most effective. Other interesting terms are those having a factor $r$ which is expected to be small, for instance after new results from pure scientific research has become available.

It is made clear that the necessary approximations of eq. (25) through (29) results in higher calculated values of the exceedance probability of departures from the true values of the discharge term. Consequently more efforts are needed to meet equation (16) being the price that has to be paid in that no sufficient information was gained about the way in which the error distributions of each term in the water balance operate simultaneously on the final result.

\section{References}

Bloemen, G. W., 1968. Determination of constant rate deep recharge or discharge from groundwater level data. Techn. Bull. I.C.W., 53.

Feller, W., 1962. An introduction to Probability Theory and its Applications. Vol II. Wiley, New York.

Kendall, M. G. and A. Stuart, 1961. The advanced theory of statistics. Pt II. Griffin, London.

Levy, H. and F. Lessman, 1959. Finite difference equations. Pitman, London.

Parrat, L. G., 1961. Probability and experimental errors in science. Wiley, New York.

Weerd, B. van der, 1965. An apparatus to measure seepage into and out of ditches. Med. I.C.W. 95 (Dutch with English summary). 